\title{
“CAPOEIRA É PRA HOMEM, MENINO E MULHER": ANGOLEIRAS ENTRE A COLONIALIDADE E A DESCOLONIZAÇÃO
}

Paula Juliana Foltran ${ }^{1}$

\begin{abstract}
Resumo:
A capoeira angola não é espaço estranho às mulheres. Muito embora, seja comum a qualificarem como sendo "do universo masculino", ou como propriamente masculina, o fato é que seus lugares de expressão e sua forma de organização sempre contaram com a presença de mulheres, não apenas espectadoras, mas que contribuíram ativamente para a construção e transformação desta prática cultural afro-brasileira e para o estabelecimento de uma tradição. Neste artigo quero discutir, a partir de uma imagem fotográfica da década de 1960, que retrata o famoso Mestre Pastinha (Vicente Ferreira Pastinha), observando duas alunas mulheres em treino, alguns mecanismos de exclusão e silenciamento das mulheres tanto da historiografia sobre a capoeira quanto de suas narrativas tradicionais. Para tanto, compartilho os dados e as informações levantados em pesquisa sobre a imagem, suas personagens e os eventos contextuais para além daquilo revelado no papel filme. A partir da fotografia em questão, muitos representantes mais velhos da capoeira angola narram uma história sobre a grandeza de um mestre e o início de uma nova fase na trajetória desta arte ancestral. O silenciamento das mulheres em luta me fez perguntar sobre quem seriam elas. Para tecer minha argumentação, apoio-me nas seguintes categorias: gênero, colonialidade do poder e descolonização do saber.
\end{abstract}

\section{Palavras-chave:}

Capoeira Angola - Gênero - Descolonização do Saber - História das Mulheres

\begin{abstract}
:
Capoeira Angola is not strange to women. Although it is common it to be described as masculine, the truth is that where this brasilian-african art takes place and the way it is organized, has always counted on the women's participation. And not just as spectators, as to the construction, transformation and establishment of a tradition. In this article I want to discuss, from a photographic image of the 1960s, which portrays the famous Master Pastinha (Vicente Ferreira Pastinha) observing two female studants training, the silencing of women from historiography and traditional narratives. Many stories are told in Capoeira universe about this photograph, always focusing on the role played by the great Master. It made me wonder who those women were. To support my argument, I rely on the following categories: gender, coloniality of power and decolonization of knowledge.
\end{abstract}

\section{Key-words:}

Capoeira Angola - Gender - Decolonization of Knowledge - History of Women

1 Doutoranda vinculada ao Programa de Pós-Graduação em História da Universidade de Brasília. 


\section{Introdução}

A capoeira angola ${ }^{2}$ não é um espaço estranho às mulheres. Muito embora, seja comum que a qualifiquem como sendo "do universo masculino", ou como propriamente masculina, o fato é que seus lugares de expressão e sua forma de organização sempre contaram com a presença de mulheres, não apenas espectadoras, mas que contribuíram ativamente para a construção e transformação desta prática cultural afro-brasileira e para o estabelecimento de uma tradição. Neste artigo quero discutir, a partir de uma imagem fotográfica da década de 1960, alguns mecanismos de exclusão e silenciamento das mulheres tanto da historiografia sobre a capoeira quanto de suas narrativas tradicionais. Para tanto, compartilho os dados e as informações levantados em pesquisa sobre a imagem, suas personagens e os eventos contextuais para além daquilo revelado no papel filme.

A imagem a que me refiro está reproduzida abaixo. Nela vemos três pessoas envolvidas no que parece ser uma aula de capoeira.

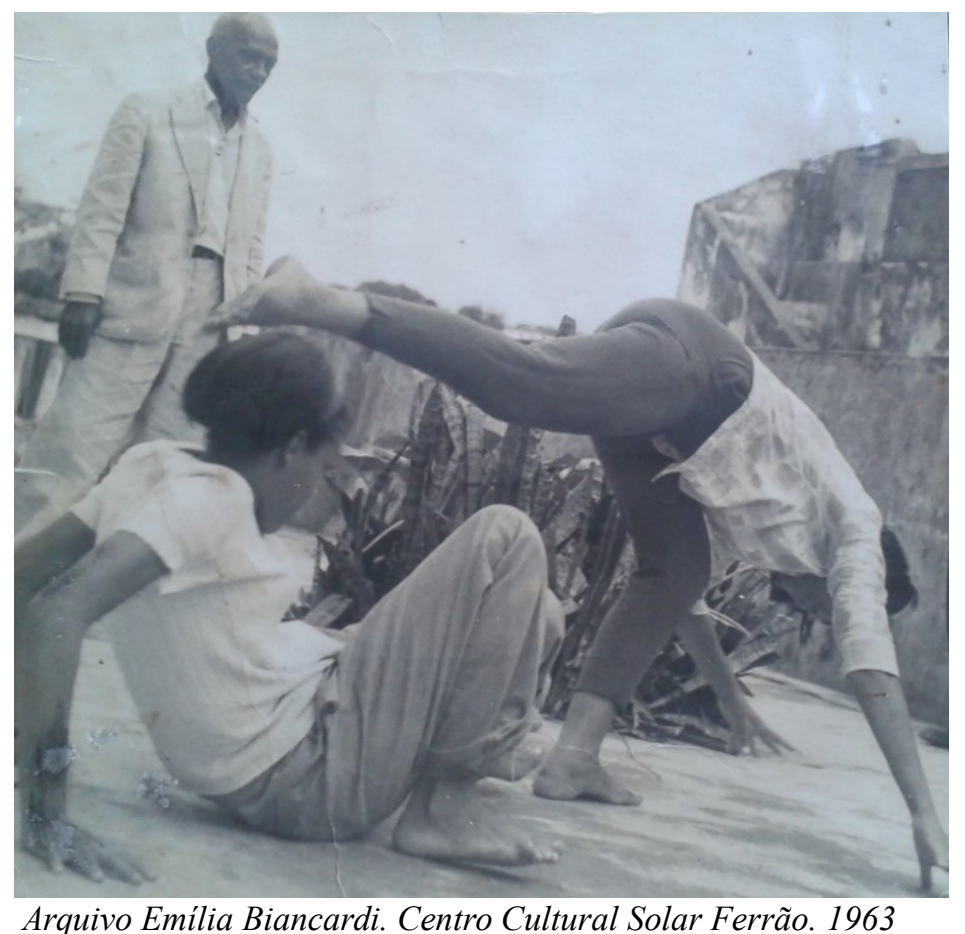

2 "Capoeira angola" se refere a uma vertente da capoeira que passou a ser popularmente conhecida por este qualificativo, angola, a partir do aparecimento e estabelecimento da luta regional baiana, a Capoeira Regional, criada por Manoel dos Reis Machado, o Mestre Bimba, na década de 1930. Este artigo leva em consideração tão somente as experiências relacionadas diretamente ao campo da capoeira angola, já que a sociabilidade e as inter-relações no universo da Regional acontecem de modo muito próprio e particular, não sendo possível a transposição da análise. 
Um professor que observa (o Mestre Pastinha ${ }^{3}$ ) e duas alunas em movimento. Antes, porém, de adentrarmos em sua análise, passo a algumas explicações contextuais.

Já há algum tempo, talvez desde a década de 1990, praticantes da capoeira angola têm refletido, mesmo que esporádica e internamente aos seus grupos de treino, a presença das mulheres neste universo. Hoje já temos grupos de estudos, coletivos de mulheres e encontros específicos voltados à discussão e ao debate político do tema ${ }^{4}$. O aumento da dedicação à reflexão sobre as assimetrias de gênero na capoeira angola acompanha o aumento exponencial da participação de mulheres, desde a década de 1970/80. Cada vez mais as academias contam com um número equivalente dos dois sexos. Contudo, quanto mais alto subimos nas hierarquias da capoeira, menor é o número de mulheres ${ }^{5}$. Aliás, elas, dentre os menos graduados (aqueles que assumem certas funções nas academias), normalmente, estão presentes nas atividades relacionadas ao cuidado, limpeza, organização, decoração, agenda, secretariado, dentre outras que são comuns à conhecida e mais ampla divisão sexual do trabalho. Também não é acompanhado por um aumento na produção de narrativas que envolvam o protagonismo de mulheres.

Inegável, porém, é a busca por referências por parte de angoleiras. Não à toa vemos a multiplicação de seus coletivos. Qualquer fotografia antiga ou anedota contada sobre uma mulher que poderia ter sido capoeira tem grande valor nesses meios. Tanto assim que a fotografia referida enfeita paredes de academias diversas. Não menos interessante é que poucos parecem conhecer as personagens nela representadas e, tampouco, a história por trás da imagem. Em uma roda de capoeira angola em comemoração ao Dia Internacional da Luta das Mulheres, aqui em Brasília, no ano de 2015 , foi contado ${ }^{6}$ pelo mais velho presente que a participação das mulheres na capoeiragem

3 Vicente Ferreira Pastinha, o Mestre Pastinha, é grande nome da história da capoeira angola na Bahia, considerado um dos guardiães da tradição da capoeira no contexto de esportização da década de 1930 . Seu nome qualifica uma linhagem da capoeira angola que é reconhecida e admirada no mundo todo.

4 Alguns exemplos: o encontro de capoeira angola Chamada de Mulher, promovido a cada dois anos pelo Instituto Nzinga de Estudos da Capoeira Angola e de Tradições Educativas Banto no Brasil, ele próprio um grupo dedicado à reflexão política e de gênero na capoeira. O Coletivo Angoleiras do Cerrado, cuja existência foi curta, mas que promoveu três importantes encontros de debate e discussão sobre a mulher na capoeira entre 2014 e 2015 em Brasília. Também periodicamente ocorre o Encontro das Mulheres na Capoeira, promovido pela Fundação Internacional da Capoeira Angola (FICA).

5 BARBOSA, Maria José Somerlate. A Mulher na Capoeira. In: Arizona Journal of Hispanic Cultural Studies. Vol. 09. Ano 2005.

6 Muitas das informações aqui apresentadas e discutidas foram coletadas em vivências da capoeira angola, em Brasília e em Salvador. Desde 2013 mantenho cadernos de notas onde transcrevo as principais conversas ou histórias que ouço de mestres, mestras e capoeiristas mais velhos/as. No caso da narrativa sobre a qual me apoio para escrever este texto, ela foi ouvida pela comunidade angoleira e por representantes do movimento feminista e negro do DF na ocasião da abertura da Exposição do Festival da Mulher Afro-Latina-Americana e Caribenha (Latinidades), no dia 08 de março de 2015. Para tal 
é antiga e que o grande Mestre Pastinha teria tido papel fundamental neste sentido. Segundo este relato, teria sido na década de 1950 que o já então reconhecido Mestre teria aberto sua academia às mulheres e que a partir disso o número de praticantes do sexo feminino teria iniciado sua ascendência. Ele cita a fotografia aqui reproduzida e afirma que Mestre Pastinha "abriu as portas da capoeira" para as mulheres, permitindo que treinassem. Afirmou, ainda, que ele havia sofrido discriminação por ter aberto sua academia a mulheres, já que elas não deveriam sequer adentrar o Pelourinho. Apesar disso, o Mestre persistiu e teria inaugurado uma nova época na capoeira angola.

Ouvir esta narrativa acerca de parte tão importante da história da capoeira, que diz respeito às transformações da participação de mulheres na elaboração desta dinâmica cultural e, quiçá, da própria capoeira, me trouxe um incômodo profundo. Motivada a conhecer as contribuições de mulheres a esta tradição, parti da imagem e da história narrada para buscar outros indícios que contassem, no mínimo, quem seriam as duas jovens retratadas. O artigo está dividido em três partes. A primeira discute o referencial teórico e metodológico para a elaboração de uma releitura deste curto, mas fundamental, trecho da história da capoeira angola. É neste ponto que explicito as categorias de análise: gênero e tecnologias do gênero; colonialidade e descolonização do saber. No segundo ponto, compartilho os dados, informações e contos ouvidos na pesquisa, em narrativa que condensa o percurso, as análises e a releitura da fotografia. Por fim, um breve comentário não de conclusão, mas de encerramento desta etapa de reflexões.

\section{Preparando a roda da capoeira: referenciais e categorias de análise}

Ainda que se reconheça, e o movimento negro feminista é enfático nisso ${ }^{7}$, que as mulheres negras não vivenciaram a dicotomia público-privado da mesma forma que mulheres brancas, isso não tem se desdobrado no amplo reconhecimento de que elas não só estavam presentes nas ruas, como também a dinamizavam econômica, política e culturalmente ${ }^{8}$. Na produção do conhecimento, tanto no campo dos saberes populares e tradicionais, quanto no da historiografia, o sujeito mulher,

ocasião, o Grupo Nzinga de Capoeira Angola promoveu uma roda e seu professor, "o mais velho", discursou sobre a questão das mulheres na capoeira e citou a referida imagem.

7 Sobre a discussão, ver: CARBY, Hazel. Mujeres Blancas. ¡Escuchad! El feminismo negro y los limites de la hermandad femenina. In: SOJOURNER, Truth. et. al. (org.). Feminismos Negros: una antología. Madrid: Traficantes de Sueños, 2012. DAVIS, Angela. El legado de la esclavitud: modelos para una nueva feminidad. In: DAVIS, Angela. Mujeres, raza y clase. Madrid: Akal, 2005.

8 LANDES, Ruth. A cidade das mulheres. Rio de Janeiro: Civilização Brasileira, 1967. 
ou mulheres, é costumeiramente silenciado, ocultado e diminuído em importância ${ }^{9}$. Diversas intelectuais feministas vêm questionando o silêncio da produção historiográfica quanto à existência das mulheres. É bem representativa de tal preocupação a frase de Mary Del Priori ${ }^{10}$ ao responder para que serve a história das mulheres: "para fazê-las existir, viver e ser". As estratégias de abordagem teórico-metodológicas para tratar da história das mulheres são muito diversas e dependem em grande medida do entendimento que se faz da categoria de gênero, tanto quanto da de mulheres.

Em recente diálogo com o pesquisador Josivaldo Pires de Oliveira ${ }^{11}$ sobre a "ausência" de mulheres na historiografia da capoeira e em todos os seus meios de perpetuação da tradição ele me propôs um desafio. Mostrando meia dúzia de fotos/desenhos e relembrando algumas canções, me perguntou se ali eu via mulheres. A resposta não poderia ser outra: eu as percebia e, portanto, sua ausência pode estar sendo construída num imaginário povoado por elas.

Aqui reproduzo uma das imagens que apreciamos naquele dia, uma ilustração de Carybé, onde vemos o cenário da capoeiragem: o jogo, a música e também as mulheres.

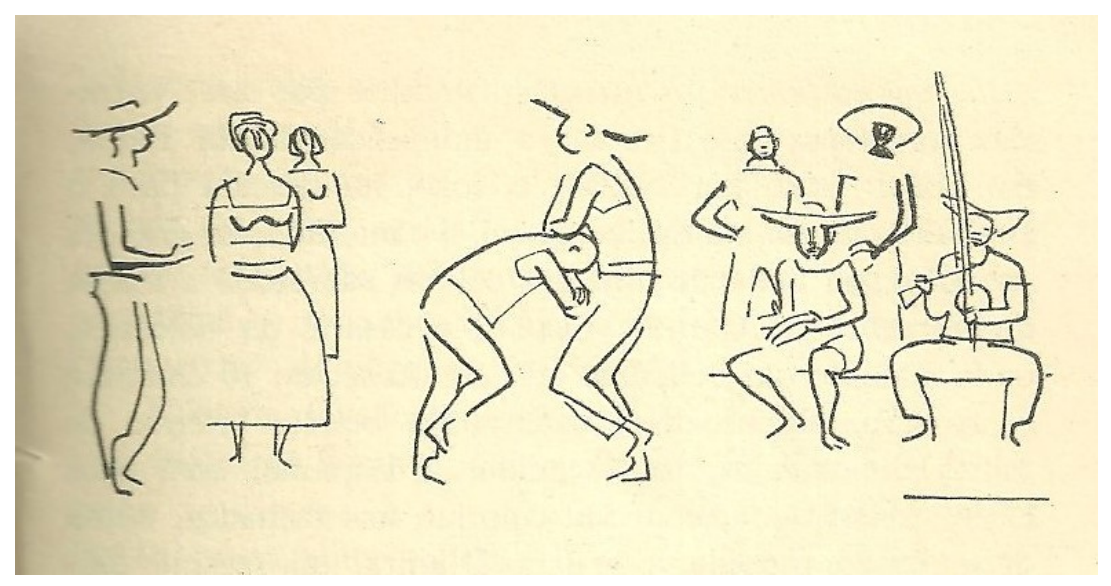

Capoeira, de Carybé (pinacoteca ${ }^{\circledR}$ carybé)

9 MUNIZ, Diva do Couto Gontijo. Mulheres na historiografia brasileira: práticas de silêncio e inclusão diferenciada. In: STEVENS, Cristina et. al. Gênero e feminismos: convergências (in)disciplinares. Brasília: Libris, 2010. pp. 65-79.

10 PRIORE, Mary. História das Mulheres: As vozes do silêncio. In: FREITAS, Marcos Cezar de (org.). Historiografia Brasileira em Perspectiva. São Paulo: Contexto, 1998.

11 O Mestre Bel, historiador e autor do livro: OLIVEIRA, Josivaldo P. de \& LEAL, Luiz Augusto P. Capoeira, Identidade e Gênero: Ensaios sobre a história social da Capoeira no Brasil. Salvador: EDUFBA, 2009. 
Este exemplar da iconografia da capoeira é um dentre vários que mostram pessoas praticando e observando. Nela vemos mulheres nas proximidades, como nas proximidades estão aquelas que surgem nas canções, das mais tradicionais às reinterpretações atuais: "cai cai Catarina / caia no mar / venha ver Idalina"; "ê vai você vai você / dona Maria como vai você"; "dona Maria o que vende aí / é coco e pipoca que é do Brasil". A contradição está justamente nesta presença que se torna ausente nos processos de construção de um saber sobre a capoeira angola, seja ele de cunho tradicional-popular, seja de cunho historiográfico ${ }^{12}$.

O próximo desenho é ainda mais ilustrativo do apagamento das mulheres na capoeira. Estão representadas como penumbras em branco, enquanto o foco dado pelas cores e pelos detalhes recai sobre os homens, em primeiro plano.

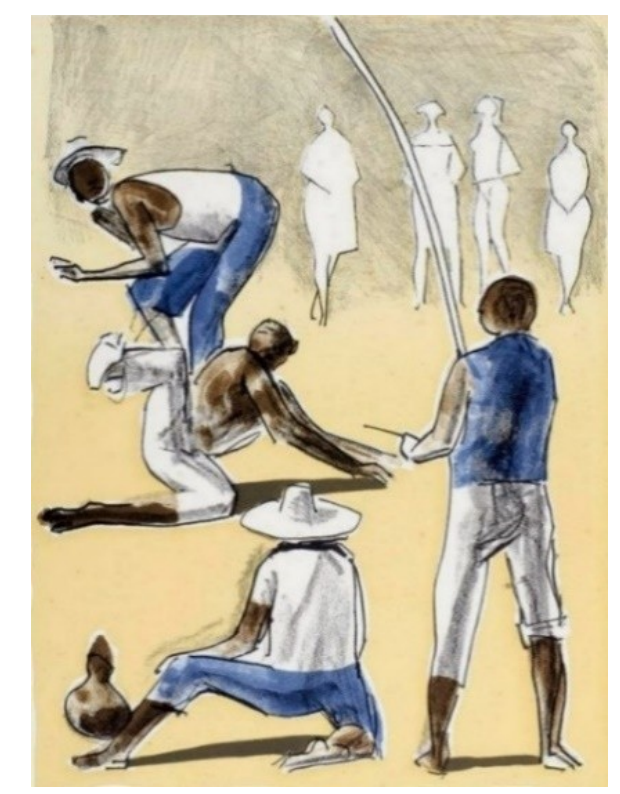

Capoeira, de Carybé (pinacoteca ${ }^{\circledR}$ carybé)

Para discutir esses processos me apoio em algumas categorias, provenientes de vertentes teóricas específicas, desenvolvidas por linhas de pensamento diferentes, mas que se encontram em

12MUNIZ, Diva do Couto Gontijo. Idem. NEPOMUCENO, Bebel. Mulheres Negras: protagonismo ignorado. In: PINSKY, Carla Bassanezi; PEDRO, Joana Maria (org.). Nova História das Mulheres no Brasil. São Paulo: Contexto, 2012. pp. 382-409. RAGO, Margareth. Epistemologia Feminista, gênero e história. In: PEDRO, Joana Maria (org.) Masculino, Feminino e Plural. Florianópolis: Editora Mulheres, 2000. pp. 21-42. SCOTT, Joan. História das Mulheres. In: BURKE, Peter. A escrita da história: novas perspectivas. São Paulo: Editora da UNESP, 1992. SCOTT, Joan. Prefácio à Gender and Politics of History. Cadernos Pagu. Campinas: Unicamp/NEG/PAGU, 1994, n. 3, pp. 11-27. 
confluência numa perspectiva que considero interessante. A primeira categoria que mobilizo é gênero. A partir de Joan Scott e Teresa de Lauretis ${ }^{13}$, estou considerando, aqui, gênero como o conjunto de efeitos produzidos em corpos, comportamentos e relações sociais, ou o saber a respeito das diferenças sexuais. Tal saber não é apenas um conjunto de ideias e definições, abarcando estruturas, práticas e instituições sociais. Ou seja, as relações de poder decorrentes desta produção, tendo em vista as investidas conflitantes e diferenciais dos discursos sobre homens e mulheres. Esta é uma compreensão compartilhada por outras autoras feministas a partir de uma perspectiva pósestruturalista. Especificamente para a análise que proponho quero usar a noção de Tecnologias do Gênero $^{14}$. A capoeira angola enquanto prática social pode ser entendida como tal, na medida em que produz o gênero e suas representações na mesma proporção em que é por ele produzido.

Segundo Teresa de Lauretis, a construção do gênero ocorreria por meio de tecnologias e de discursos institucionais com o poder de controlar o campo do significado social e assim produzir, promover e implantar representações de gênero. Segundo seu argumento, os termos para uma construção alternativa existem e podem ser acionados. São encontrados nas margens dos discursos hegemônicos para manter a linha de estudo, como resistência ao poder dominante ou apresentada como releitura. Por meio dos cantos, das poesias, das histórias e dos significados atribuídos aos instrumentos e demais elementos do ritual da roda da capoeira, são promovidas e construídas representações sobre mulheres e sobre homens. Isso não se faz do nada. Contamos com um arsenal interpretativo anterior, repleto de categorias cristalizadas que mobilizamos nos processos de reconhecimento e interpretação. As formas de pensamento e produção de conhecimento estão colonizadas com categorias modernas que se querem universais, tal qual o binarismo de gênero. Dele nos valemos na produção de conhecimento e tal conhecimento se torna produtor do gênero, como o faz a historiografia ou as narrativas tradicionais vinculadas à capoeira angola.

A narrativa apresentada pelo capoeirista mais velho em torno daquela imagem das duas jovens jogando capoeira sob a supervisão do Mestre Pastinha, hegemônica no contexto da capoeira, obedece a esta lógica e parte de uma compreensão anterior sobre o conceito de mulher e de homem, inclusive os valores e papéis sociais informados pelo binarismo de gênero. Ainda que fosse atrativa a fala a respeito da agência (ou do protagonismo) de Pastinha nesta suposta mudança no perfil dos

13 SCOTT, Joan. Idem. LAURETIS, Teresa de. A Tecnologia do Gênero. In: HOLLANDA, Heloisa Buarque (org.). Tendências e Impasses: o feminismo como crítica da cultura. Rio de Janeiro: Rocco, 1994.

14 LAURETIS, Teresa de. Idem. 
praticantes da capoeira angola, sobretudo, por se tratar de figura "classificada" 15 " na roda da capoeira, aquelas mulheres não mereceram na narrativa qualquer atenção. Não tinham nome, idade, razões para ali estar, não se articularam politicamente, não formularam estratégias, não agiram. São apenas objetos passivos da ação libertadora de um grande homem. Esse sim, agente produtor de uma história. Mas é possível romper esse ciclo e propor um novo olhar. As outras noções a que recorro na construção do meu argumento estão no campo dos estudos subalternos e pós-coloniais. A capoeira sendo uma manifestação cultural diaspórica ${ }^{16}$, isto é, inserida no contexto de resistências e ressignificações vinculados à modernidade, pode ser melhor compreendida dentro desta proposta de análise a partir de duas categorias discutidas nos referidos campos: colonialidade do poder e descolonização do saber.

O primeiro se baseia na compreensão de que "a modernidade, o capitalismo e as Américas nascem no mesmo dia ${ }^{17}$ ". A criação das Américas é o ato constitutivo do sistema mundo moderno e a partir desse momento não é possível pensar modernidade sem colonialidade, caso contrário, o ponto de vista será eurocêntrico e unilateral. Os discursos da modernidade ocultaram a colonialidade e o que ela representa à conformação do mundo. Ela está na base, inclusive, da formação de subjetividades e identidades, uma vez que a racialização de grupos populacionais surge como justificação do sistema que se instala a partir do tráfico transatlântico ${ }^{18}$. Disso se desdobra a naturalização da exploração e da violência colonial, além de garantir a supremacia europeia objetiva e subjetivamente, material e espiritualmente, algo que, por isso mesmo, não se encerra com a conquista das "independências" por parte das antigas colônias 19 .

A capoeira, assim como outras práticas culturais diaspóricas, tais como o jongo, o

15 Menino preste atenção / no que eu vou dizer / o que eu faço brincando / você não faz nem zangado / não seje vaidoso / e nem despeitado / na roda da capoeira / Pastinha já tá classificado.

16ANDRADE, Bruno. Vadiação diaspórica: o jogo da capoeira com a modernidade brasileira. Doutoramento em Pós-colonialismos e cidadania global. Centro de Estudos Sociais/Faculdade de Economia da Universidade de Coimbra, 2011.

17 Mignolo, Walter D. A colonialidade de cabo a rabo: o hemisfério ocidental no horizonte conceitual da modernidade. En libro: A colonialidade do saber: eurocentrismo e ciências sociais. Perspectivas latinoamericanas. Edgardo Lander (org). Colección Sur Sur, CLACSO, Ciudad Autónoma de Buenos Aires,Argentina. setembro 2005. pp.71-103

18 SEGATO, Rita. Aníbal Quijano y la perspectiva de la colonialidad del poder. In: SEGATO, Rita. La crítica de la colonialidad em ocho ensayos y uma antropologia por demanda. Prometeo Libros: Buenos Aires, 2013. pp. 35-66. WALLERSTEIN, Immanuel. Ler Fanon no século XXI. In: Revista Crítica de Ciências Sociais, 82, Setembro 2008: 3-12

19 MBEMBE, Achille. Sair da Grande Noite. Ensaio sobre a África Descolonizada. Luanda, Angola; Ramada, Portugal: Edições Mulemba; Edições Pedago, 2014. 
maculelê e o candomblé, pode ser compreendida como elemento que tenciona a lógica e a racionalidade moderna disseminadas no bojo colonialista. Não se trata de uma sobrevivência de algo transportado pelo Atlântico, mas de traduções, ressignificações e negociações realizadas num complexo, dinâmico e violento contexto, que permitiu (re)criações referenciadas a uma ancestralidade ${ }^{20}$. A própria noção de "África” compartilhada entre os descendentes dos povos negros nasce nesta conjuntura. Apesar desses pontos de tensão e resistência, o colonialismo impôs, tal qual Boaventura de Sousa Santos defende ${ }^{21}$, uma linha abissal entre as categorias modernas e todas as outras formas de pensamento.

A descolonização do saber, portanto, diz respeito a um duplo movimento que transcende o sentido mais óbvio dado pelo termo e que encontramos em definições de dicionário, quais sejam, a gradual aquisição de independência das antigas colônias ou o ato de deixar de colonizar. Descolonizar pressupõe, por um lado, a abertura e a revalorização de formas não ocidentais de saber e geração de conhecimento, e por outro, a tessitura de novas narrativas históricas que superem a lógica do sistema-mundo europeu, norte-americano, capitalista, colonial e, não menos importante, patriarcal ${ }^{22}$. A capoeira, por si, já representa esta ruptura, conforme explicado acima. Baseada na oralidade e vivenciada numa temporalidade não linear, cronológica ou evolutiva, ela rompe com as principais categorias modernas e produz um conhecimento complexo que abarca variados campos e elementos da vida ${ }^{23}$.

Contudo, não se pode essencializar as narrativas produzidas no âmbito da capoeira, como sendo puras de uma forma de pensamento resistente e absolutamente desvinculada das categorias modernas/coloniais. Acredito que a virada que ocorreu na década de 1930, com a criação da capoeira regional, a esportização da capoeira e, mesmo dentro do movimento de resistência interna promovida pelos angoleiros, a academização (uniformização) da capoeira angola mostram isso.

20 ANDRADE, Bruno. Idem.

21 GROSFOGUEL, Ramón. La descolonización del conocimiento: diálogo crítico entre la visión descolonial de Frantz Fanon y la sociología descolonial de Boaventura de Sousa Santos. In: Actas del "IV Training Seminar del Foro de Jóvenes Investigadores en Dinámicas Interculturales (FJIDI)" del Centro de Estudios y Documentación Internacionales de Barcelona (CIDOB), Barcelona, 26-28 de enero de 2011

22 DIAZ, Martin. Racismo epistémico y monocultura: Notas sobre las diversidades ausentes en América Latina. In Revista de Epistemología y Ciencias Humanas, n. 3, Grupo IANUS, Docentes de la Universidad Nacional de Rosario y la Universidad Nacional del Litoral.

23 Diz mestre Patinho, do Maranhão, que para a roda da capoeira acontecer, muitos saberes estão envolvidos. Mestre Jaime de Mar Grande, da Ilha de Itaparica, de modo semelhante, diz que a capoeira não é só o que se vê na roda. 
Descolonizar é um processo complexo, porque requer a superação da alienação histórica a que fomos submetidos pelo controle colonial. As diferenças criadas na modernidade/colonialidade guiam e estão referenciadas nas estruturas de produção do saber. Raça, gênero e sexualidade, tais quais fundadas no sistema mundo moderno colonial, se perpetuam como instrumentos de dominação úteis ao capital e à manutenção da ordem. Muito embora, não seja possível dizer que sexo ou a sexualização de corpos voltado para a divisão social de tarefas, papéis e lugares não existisse anteriormente à colonização, concordo com a leitura de que o patriarcado colonial, com as estruturas instaladas a partir do colonialismo, é uma forma específica de dominação que surge e é imposta a partir da chegada europeia e fundação do sistema mundo moderno/colonial. Portanto, a crítica feminista proposta por Ochi Curiel ${ }^{24}$ às teorias pós-coloniais é pertinente e construtiva ao campo.

Para ela, sem usar a palavra "colonialidade", feministas vêm propondo reflexões cruciais para um saber transformador, considerando as imbricações dos diversos sistemas de dominação, como o sexual, racial, heteronormativo e de classe social, a partir de uma crítica pós-colonial. Entretanto, tais vozes são pouco conhecidas, ao menos fora do campo dos estudos de gênero e mulheres. Nesse sentido, Curiel chama atenção a um problema interno dos estudos pós-coloniais, algo que Stuart Hall já reconheceu no campo dos estudos culturais, qual seja: a ausência de uma reflexão crítica que aprofunde a questão das mulheres. No seu ponto de vista, quando o Centro de Estudos Culturais quis "abrir as portas” às mulheres e suas contribuições teóricas, elas se recusaram e, em seguida, "arrombaram a janela", explicitando as relações patriarcais do Centro ${ }^{25}$. De fato, as tentativas de abrir espaço aos subalternos, no masculino, obedecem às normatizações patriarcais, machistas e androcêntricas. Portanto, penso ser interessante a confluência das categorias que quero mobilizar para discutir um momento da história da capoeira angola a partir da fotografia que apresentei, lançando luz aos processos de silenciamento de mulheres na produção de conhecimento tanto tradicional-popular quanto historiográfico.

24 CURIEL, Ochy. Crítica poscolonial desde las práticas políticas del feminismo antirracista. In: Revista Nómadas. $\mathrm{N}^{\mathrm{o}} 26$ Abril. 2007. Universidad Central, Colombia

25 HALL, Stuart. Da Diáspora: Identidades e Mediações Culturais. Editora UFMG: Belo Horizonte, 2013. 


\section{Entre a colonialidade e a descolonização: relendo a imagem, recontando a}

\section{história}

Ao ver a fotografia pela primeira vez, sem conhecer as pessoas nela retratadas (a não ser o Mestre Pastinha), imaginei diversas situações e enredos que pudessem explicá-la. As possibilidades eram inúmeras. Então me dei conta de que a imagem não tinha um sentido autoevidente. Quem a vê lhe confere sentido, significado e tece uma narrativa a partir disso. Neste ato, mobilizamos categorias pré-significadas em nosso arsenal interpretativo. Por exemplo, há um homem e duas mulheres. Homem e mulher também não são autoevidentes, mas se evidenciam porque temos um conceito anterior (descritivo e normativo) que diz o que deve ser um homem e o que deve ser uma mulher, isso de forma simplória. O mesmo ocorre em tudo na fotografia, do vestuário ao sentido político.

Ao narrar um episódio que teria marcado a entrada de mulheres na capoeira angola, aquele capoeirista mais velho, apoiado nos significados hegemônicos, mobilizou todos os sentidos que estão ligados ao homem e à mulher, já que sexo é uma construção social que não se resume a uma diferença focada nos órgãos genitais. Junto vieram os valores: homem ativo e protagonista. Mulher passiva e permitida. A situação retratada (duas mulheres jogando capoeira) só ocorreu porque um homem atuou para tanto. Isso é perceptível nos termos usados em sua fala e no modo como articula os elementos de sua narrativa: "o Mestre Pastinha abriu as portas da capoeira às mulheres"; ao descrever a imagem foca na ação do Mestre e não na das alunas; quando cita episódio de discriminação é Pastinha quem o sofre; contra isso, o Mestre "persiste" e "inaugura uma nova época na capoeira angola”. Como já foi mencionado anteriormente, elas sequer têm um nome.

Fazendo um exercício simples de questionamento das possibilidades narrativas, e entendendo que tal exercício é uma forma de descolonizar o pensamento, por permitir a tessitura de novas narrativas históricas, perguntei quem seriam elas. Mais uma vez a crítica de Curiel é pertinente, já que esta busca é o que funda todo campo de estudos feministas, da história das mulheres e, mais importante, de releitura tendo gênero como categoria de análise histórica ${ }^{26}$. Além da pergunta, quem são elas, a narrativa "dominante" sobre este episódio ajuda a pensar a problemática. O capoeirista disse que mulheres não poderiam sequer adentrar o Pelourinho naquela época (quais mulheres?). Só se proíbe aquilo que alguém faz ou já fez. Se havia um senso

26 SCOTT, Joan. Idem. 
compartilhado de que mulheres não poderiam estar ali, é porque mulheres estavam ali ${ }^{27}$. E tal presença deve ser interpretada como subversiva, uma vez que é contrária a uma regra socialmente compartilhada. Quem subverte é quem está proibido e não quem está posicionado de forma hierarquicamente superior pelo sistema dominante de criação de sentidos.

Antes de ter contato com qualquer outro dado que pudesse explicar a fotografia, já percebia a presença de duas mulheres em lugar que não lhes era “próprio". Na década de 1960 quem poderia, seguindo as tendências normativas de sexo, raça e classe, estar na presença de um grande Mestre de capoeira, aprendendo com ele? Sabemos que os códigos de vestimenta também eram rígidos. Mulheres de calça chegava a ser, na linguagem popular, ilustração de situações fora de lugar ou de inversão malvista de papéis: na sua casa quem veste calças é sua mulher? Somente esta mudança de foco na observação da imagem em questão permite, se não a inclusão de uma voz silenciada, ao menos uma ampliação dos sentidos percebidos. O subalterno, nesta micro-história, só poderia se fazer presente por meio da superação do dualismo simplista das categorias modernas de sexo ou do binarismo hierárquico de gênero.

Não se trata de falar de mulheres como se fala de homens: como se fossem um todo homogêneo, universal e essencialmente dado, único. Mas de inclúi-las em esquemas complexos de análise social, capazes de compreender a própria história como lugar de produção do gênero, tanto quanto outras formas de narrativa histórica, como a capoeira. Afinal, a capoeira enquanto expressão de uma cultura híbrida ${ }^{28}$ ginga entre a colonialidade (por assumir categorias modernas em sua organização e produção de saberes) e a descolonização (por se fundar na contracorrente da racionalidade moderno-colonial). Tampouco se trata de corrigir a história. As mulheres não conformam um momento à parte do mundo, de modo que suas "esparsas" contribuições poderiam ser narradas igualmente à parte das inter-relações sociais, culturais e políticas mais complexas. Parafraseando Curiel, quando entendemos a descolonização como mecanismo de reconhecer e

27 LANDES, Ruth. Idem. Além deste clássico livro de Ruth Landes, não faltam informações jornalísticas e policiais da presença de mulheres nas ruas de Salvador, em especial nas zonas centrais, onde o comércio era intenso. Desde séculos passados, mulheres negras já eram retratadas em imagens e desenhos. Em pesquisa no Acervo Público do Estado da Bahia, ao longo do ano de 2016, por exemplo, encontrei mais de 200 referências a mulheres atuando nas ruas do centro histórico de Salvador.

28 Culturas Híbridas é conceito trabalho Homi Bhabha. Para ele diferenças entram em contato no entretempo da modernidade, sendo a diáspora um catalizador de tal movimento. Os embates produzidos performaticamente são negociações, resultam em hibridizações. São processos socioculturais nos quais estruturas ou práticas discretas, que existiam de forma separada, se combinam para gerar novas estruturas, objetos e práticas. Ver: BHABHA, Homi K. Locais da cultura, em BHABHA, Homi K. $O$ local da cultura. Belo Horizonte: Editora UFMG, 2003. Pp. 19-42. 
registrar as produções teóricas e práticas provenientes de grupos subalternizados, racializados e, neste caso, sexualizados, é fundamental que também sejam reconhecidas, valorizadas e registradas as histórias de tantas mulheres cujas lutas e protagonismos serviram para construir teorias, tradições e saberes.

Muito embora o incômodo causado pela descrição que ouvi da velha fotografia, sem legendas, sem concretudes, tenha me incentivado a uma busca por pessoas que pudessem revelar mais informações para além daquelas presentes no papel filme já desbotado, foi numa dessas coincidências da vida que obtive o primeiro dado que descortinou toda a história posterior. Visitando uma academia amiga, de grupo de capoeira angola admirado, vi uma fotografia na parede, mas não aquela que tinha tomado conhecimento alguns meses antes:

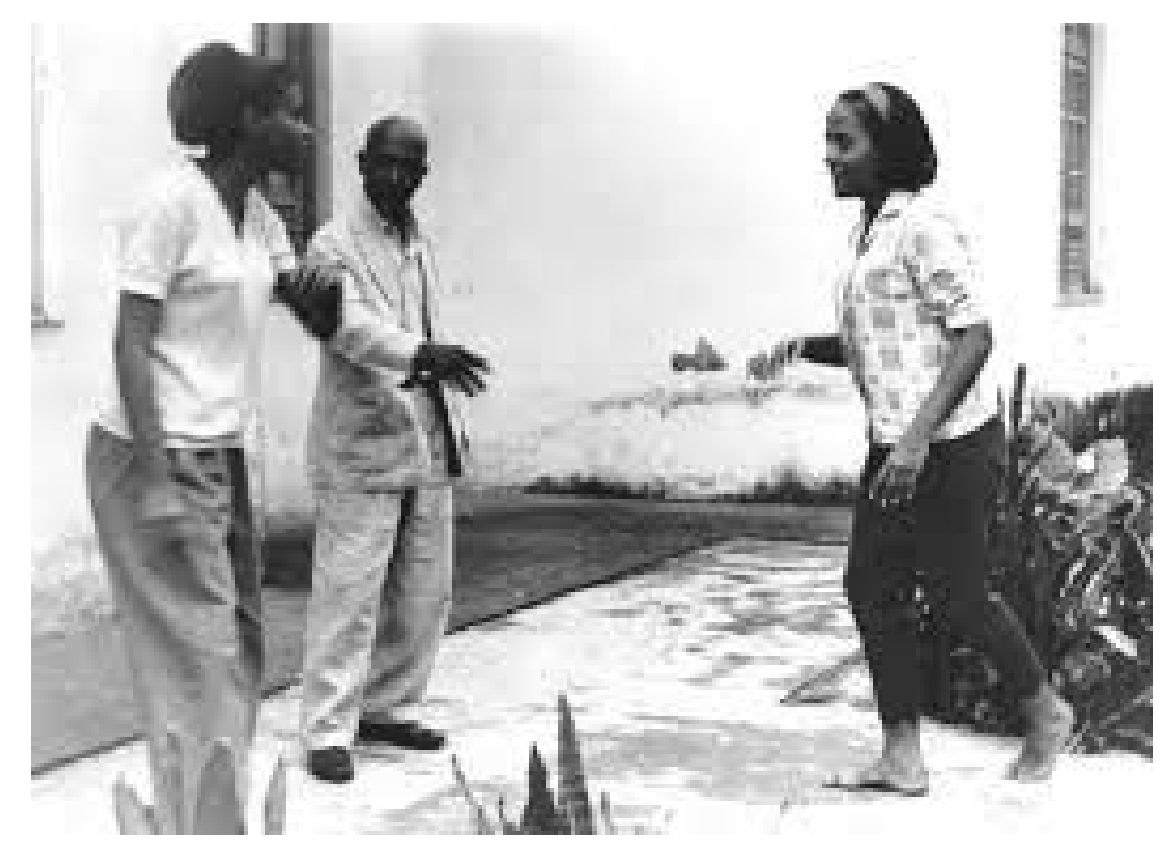

Acervo Emília Biancardi. Centro Cultural Solar Ferrão. (1963)

Me surpreendi por haver outra imagem do que pareceu ser o mesmo dia. Também sem legendas e informações adicionais, a fotografia era, segundo capoeiristas daquela academia, uma grande referência às mulheres que ali treinavam. Perguntei se alguém poderia saber algo que me levasse a elas, e o professor do lugar disse se tratar de Emília Biancardi. Uma busca rápida na internet revelou que Emília, uma etnomusicóloga baiana de grande valor na cena cultural soteropolitana, era branca, o que não equivale às mulheres representadas nas imagens. Essa mesma busca me revelou a produção teórica desta pesquisadora. Dois de seus livros citados e que pude 
adquirir posteriormente são "Raízes Musicais da Bahia" e "Olelê Maculelê"29. Na rede também encontrei algo sobre o conhecido grupo Folclórico "Viva Bahia". Pela primeira vez algo familiar estava ligado à fotografia, mas não de forma evidente. A terceira e última, e mais completa, informação que encontrei sobre o nome de Emília é que sua coleção de instrumentos musicais tradicionais, cultivada ao longo de mais de 40 anos de pesquisa e trabalho, fora doada ao Centro Cultural Solar Ferrão, em Salvador, e que a própria preparava a inauguração do espaço cedido à coleção para visitações.

Alguns telefonemas mais tarde, eu conhecia esta excepcional mulher, sua coleção de instrumentos e o acervo documental que reuniu e organizou sobre sua atuação cultural, desde a fundação do Viva Bahia, em 1962, até os dias atuais. Não sendo meu foco, no momento, discutir a trajetória de Emília Biancardi, mas apresentar informações capazes de colaborar com a construção de uma narrativa menos androcêntrica sobre o episódio representado na fotografia, tentarei me valer tão somente dos dados relacionados diretamente àquele dia do ano de 1962, data precisada no verso da fotografia original, guardada no acervo que leva o nome de Emília Biancardi, no museu Solar Ferrão.

Após assumir a cadeira de Cantos Orfeônicos do Instituto Normal Isaías Alves (ICEIA), em 1962, Emília Biancardi criou um grupo de estudos e experimentação musical voltado à cultura popular baiana, o Viva Bahia. O objetivo do grupo era agregar o corpo discente do ICEIA para o estudo do folclore baiano em suas complexas formas de representação: os rituais, a musicalidade, a estética, os instrumentos. Para além do estudo e da pesquisa, os envolvidos com o grupo passavam por vivências com grandes mestres populares, aprendendo e praticando sua arte. Após um período de aprendizado, as alunas e alunos realizavam apresentações, em princípio para a comunidade escolar. Emília Biancardi, em conversa que tivemos em meados de 2015, relembra ter sido uma surpresa tanto para ela quanto para as demais pessoas envolvidas no projeto, a expansão das apresentações ao púbico em geral. O Viva Bahia tornou-se conhecido nacional e internacionalmente e seu legado se encontra vivo ainda hoje em grupos folclóricos como o Olodum.

A capoeira, além da puxada de rede, do candomblé, do maculelê, do samba duro e do samba de roda, fez parte das expressões culturais afro-baianas estudadas e vivenciadas pelos participantes do Viva Bahia. Alguns dos mestres que contribuíram com o grupo são: Mestre Popó (José de

29 BIANCARDI, Emília. Olelê Maculelê. Edição pela autora: Salvador, 1989. BIANCARDI, Emília. Raizes Musicais da Bahia. Omar G: Salvador, 2000. 
Almeida Andrade, de Santo Amaro), para o maculelê; Negão Doni (Gilberto Nonato Sacramento), Dona Coleta de Omolu (Clotildes Lopes Alves) e Seu Edson (Edson Santos) para o candomblé; Mestre Acordeon (Ubirajara de Almeida), Camisa Roxa (Edivaldo Carneiro dos Santos) e Pastinha (Vicente Ferreira Pastinha) para a capoeira. Aliás, no universo da capoeiragem a presença e participação de mestres é bem extensa, e as trocas entre tais figuras e o Viva Bahia merecem o maior destaque, uma vez que muito do que conhecemos hoje como tradição da capoeira, seja ela angola ou regional, surge ou se expande no contexto dos grupos folclóricos.

Os mestres João Grande, João Pequeno, Boca Rica, Curió, Pelé da Bomba, Lua de Bobó, Lua Rasta, Bigodinho, Gato Preto, Caiçara e Bimba são alguns dos grandes nomes citados por Emília que, segundo ela, alimentaram o Viva Bahia e dele se nutriram, levando para suas academias elementos antes presentes apenas nas apresentações folclóricas. A animada etnomusicóloga conta, em sua genial simplicidade, que por não contar com recursos públicos, sobretudo no início dos trabalhos, ainda na década de 1960, ela montava um palco único que agregava os elementos visuais, estéticos e rito-instrumentais de cada tradição. Ou seja, a cada ato, por assim dizer, o palco não era alterado, de modo que da puxada de rede ao maculelê, os instrumentos e ornamentos permaneciam os mesmos. Se pensarmos que até 1968 , conforme registrado na obra de Waldeloir Rego ${ }^{30}$, o atabaque não fazia parte das rodas de capoeira, bem como não era generalizada a presença do recoreco e do ago-go, podemos levantar a hipótese de que os espetáculos do Viva Bahia, ou pelo menos o formato de apresentações inaugurado por Emília Biancardi, pode ter contribuído com a conformação da bateria de angola tal qual a conhecemos nos dias de hoje. Algo que merece aprofundamento e pesquisa.

A falta de financiamento não representou um problema insuperável para Emília Biancardi, que investiu, com o apoio de sua mãe, Dona Margarida, os recursos familiares para manter as apresentações e as pesquisas do Viva Bahia. Conforme já disse acima, o grupo, para promover os espetáculos, passava por vivências com os mestres de cada tradição. Foi no contexto de tais vivências que entrou em cena Mestre Pastinha. Segundo relato de Emília, ela fora ao Pelourinho conhecer pessoalmente a academia do já famoso Mestre e com ele conversar e aprender sobre a capoeira de angola. Pastinha é descrito por ela como um homem muito educado e doce, aberto ao diálogo e generoso. Emília o contratou, então, para ensinar a um grupo de estudantes, dentre os quais, algumas mulheres. Pastinha aceitou o acordo, mas pediu para que as aulas dadas às mulheres

30 REGO, Waldeloir. Capoeira angola: ensaio sócio-etnográfico. Salvador: Itapoã, 1968. 
não acontecessem em sua academia. Como as demais vivências, a da capoeira aconteceu no quintal da casa de dona Margarida, mãe de Emília.

As duas imagens abaixo foram registradas no mesmo quintal e ano. A primeira diz respeito a uma aula sobre a dança dos orixás nos rituais do candomblé, dada por Dona Coleta de Omolú:

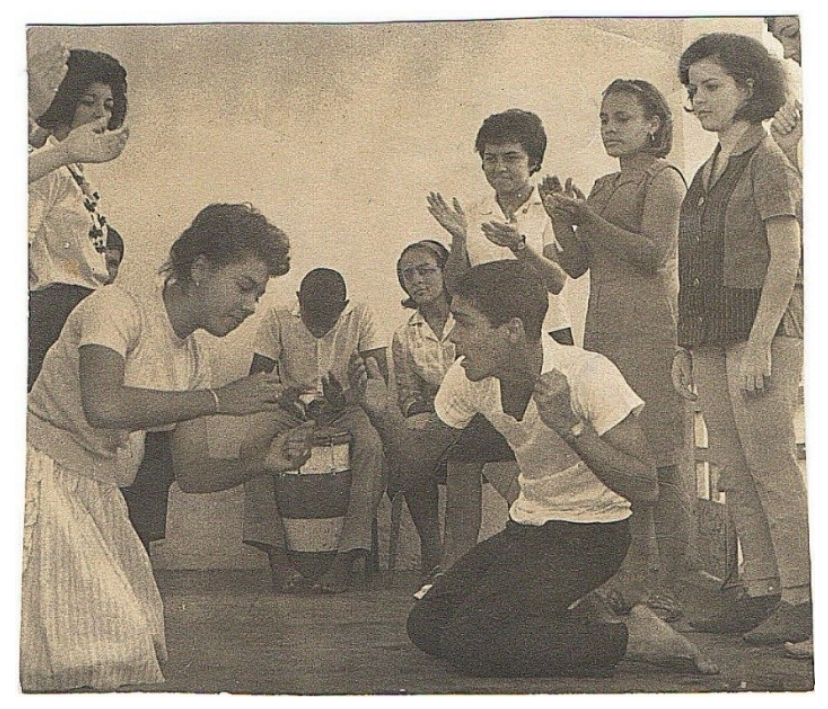

Dona Coleta de Omolu - Acervo Emília Biancardi (1963)

Esta segunda imagem mostra o senhor Canapum ensinando a puxada de rede ao grupo de estudantes do Viva Bahia:

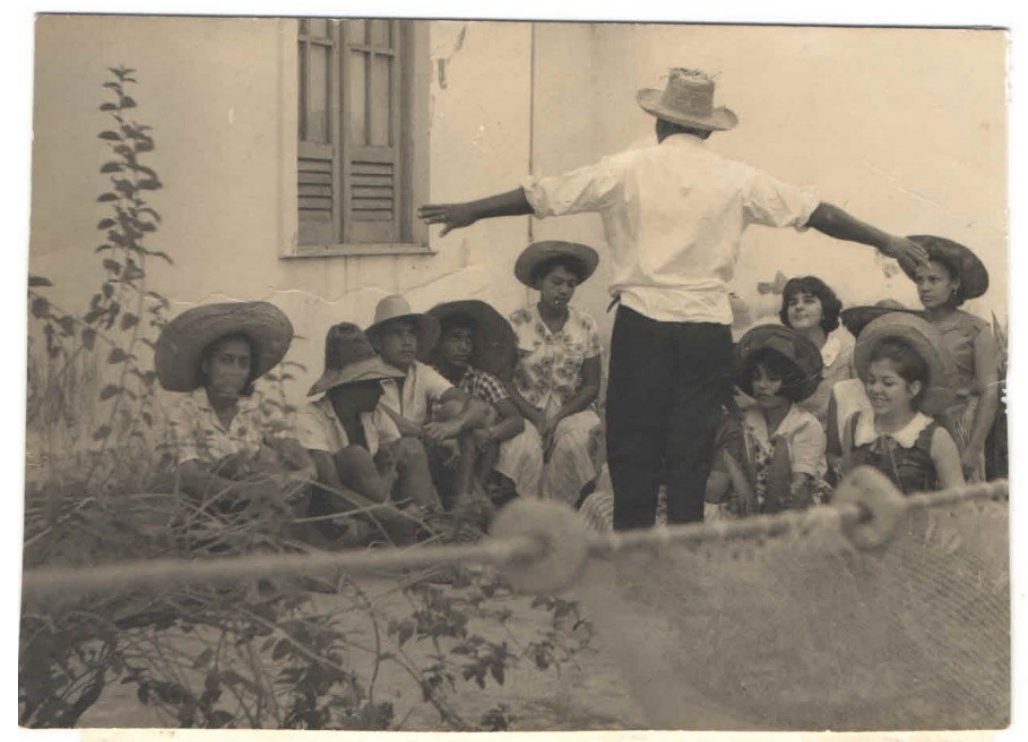

Senhor Canapum, Puxada de Rede - Acervo Emília Biancardi (1963) 
Com uma memória viva, Emília descreveu aqueles dias de vivência no quintal de sua casa como intensos de aprendizado e crescimento, uma oportunidade transformadora para os que puderam participar. As duas jovens que aparecem na fotografia de 1962, junto ao Mestre Pastinha, são Helena Santos e Luísa Sampaio. Aliás, é justo anotar que Emília Biancardi contratou um fotógrafo, já que naquele tempo não eram comuns e populares as máquinas fotográficas, de modo que poucas imagens existem dos primeiros anos do Viva Bahia. Esta é uma informação interessante por mostrar a sagacidade da professora que soube guardar a memória de sua trajetória que se entrelaça às transformações sociais, políticas e culturais de mais de meio século (já que ainda se encontra em atividade na cidade da Bahia) em Salvador e outras cidades do mundo. Desconhecendo o paradeiro de Helena Santos, Emília articulou meu encontro com Luísa Sampaio e dois chopes e um café mais tarde, nos jardins do Teatro Castro Alves, finalmente ouvi a versão da história daquela fotografia conforme o ponto de vista de quem efetivamente viveu aquele momento.

Estudante do ICEIA à época da fundação do Viva Bahia, Luísa se inscreveu para participar do grupo de estudos. No início a ideia era pesquisar apenas a puxada de rede e a capoeira. Conta que foi a capoeira o que imediatamente lhe chamou atenção para decidir participar. Ao contrário do que ouvi 50 anos depois daqueles dias, não teria sido por iniciativa do Mestre Pastinha que as aulas para as duas mulheres aconteceram. Conta que Emília foi até o Mestre para lhe oferecer pagamento pelas aulas e que isso só ocorreu porque as alunas teriam, antes, demonstrado interesse. "Queríamos aprender capoeira e Emília sabendo disso articulou para que acontecesse”, disse Luísa. Outra informação contraditória em relação à narrativa anterior é que Pastinha jamais teria sofrido discriminação pelas aulas. Naquela época outros mestres já ensinavam mulheres em suas academias, a exemplo de Gato Preto, conforme registrado na obra de Waldeloir Rego ${ }^{31}$. Além do mais, aquelas aulas, no quintal de Emília, foram de conhecimento de poucos.

As duas jovens treinaram com Mestre Pastinha entre 1962 e 1963 e, segundo Luísa, isso somente deixou de acontecer quando Emília optou por retirar as mulheres das apresentações de capoeira por entender que os espetáculos deveriam satisfazer ao imaginário social da época que associava a capoeira a homens. Apesar disso, ela manteve Luísa no elenco do maculelê, outra prática tida como masculina. Ela era a única mulher e relata ter sofrido muitas pauladas propositais nas mãos durante os ensaios e apresentações. O mesmo tipo de estratégia a afastou em definitivo da capoeira. Mesmo depois de ser retirada do elenco das apresentações da capoeira, Luísa continuou

31 REGO, Waldeloir. Idem. 
visitando, no Pelourinho, o Mestre Pastinha. "Eu gostava muito dele, era um homem elegante, educado, falava baixo e tinha a voz mais doce" 32 . Conta já ter sido atacada por pedras quando se aproximava da academia. Assim, aos poucos deixou de visitá-lo, algo que relata com ar de arrependimento. Afirmou que se tivesse sido outro o tempo, poderia ter continuado, mas diz se alegrar com tantas outras atividades que desenvolveu.

Foram mais de 10 anos de apresentações. Nos anos duros da ditadura chegou a ser presa, junto com os demais integrantes do grupo. Viveu em Nova Iorque por 6 meses, em turnê com o Viva Bahia na década de 1970. Neste período já era casada e tinha uma filha de 2 anos. Marido e filha permaneceram no Brasil no ano de 1974, enquanto Luísa se apresentava nos Estados Unidos, informação que desafia o binarismo de gênero lançado na interpretação androcêntrica da fotografia. Retornando a 1963, as duas mulheres que ousaram estar onde não deveriam, diante de um mestre de capoeira, vestindo calças emprestadas por seus respectivos irmãos, já dominavam os toques básicos dos berimbaus, do ago-go e do tambor. Conta que Pastinha só ensinava os movimentos a quem já tocava e cantava a capoeira. Informação condizente com o que se conta sobre o Mestre. Seu mais ilustre discípulo, o mestre João Grande, em conversa que tivermos em 2015, também cita esta metodologia de Pastinha.

Ou seja, no dia em que Emília levou um fotógrafo ao seu quintal com o intuito de registrar um treino de capoeira dado a mulheres autônomas e desejosas de aprender, Luísa e Helena já tinham conquistado o direito ao treino físico, segundo os critérios do próprio Mestre. Já estavam junto a ele há alguns meses, e com ele permaneceram por outros tantos, até que o contexto da época afastou ao menos uma das jovens. Mesmo fora das apresentações, Luísa e Helena continuaram ouvindo a frase que se tornou tradicional na abertura de cada show de capoeira do Viva Bahia: “Capoeira é pra homem, menino e mulher, só não aprende quem não quer”.

\section{Conclusão: da releitura da imagem à reescrita de uma história}

Antes de Luísa Sampaio se interessar pela capoeira oferecida como tema de estudo e vivência por um recém-criado grupo de estudos folclóricos em sua escola normalista, na década de 1960, outras mulheres já haviam se interessado pela capoeira. Mestres como João Grande, Boca Rica e Curió já me relataram causos envolvendo mulheres capoeiristas antes da década de 1940,

32 "Seu Pastinha é doce / Seu Pastinha é mel”. Corrido do Mestre Boca Rica, discípulo de Pastinha. 
período em que se consolidou a academização. O próprio Mestre Pastinha, em seus manuscritos, cita alguns nomes, pouco pesquisados: Julia Fogareiro e Rosa Palmeirão. Outras propostas de estudo sobre as mulheres na capoeira chegam até o século XIX, ou mesmo antes, aproximando a Rainha Nzinga de Angola às origens da luta. A vivência registrada naquela fotografia de 1962 tem, contudo, um contexto específico. Trata-se de um momento absolutamente diferente daquele vivido por capoeiras no século XIX, ou mesmo início do XX. Naquele ano a capoeira já havia deixado de ser prática criminal e havia ganhado o status de esporte nacional e de expressão cultural popular, presente nas festas de largo e em apresentações turístico-culturais.

O único registro anterior a 1968 que cita mulheres envolvidas neste novo modo de fazer capoeira angola, ou seja, nas academias, é o Livro de Registros do Centro Esportivo de Capoeira Angola (CECA), do Mestre Pastinha ${ }^{33}$. Em seu caderno de controle de matriculas, Pastinha anotava algumas informações sobre os alunos de sua academia, como nome, endereço, idade e profissão. O registro de $n^{\circ} 113$, referente aos anos de 1962 a 1965, é apenas a fotografia 3x4 do rosto de uma mulher. Abaixo desta foto não há qualquer informação. As outras duas mulheres inscritas no Livro de Registro de Pastinha são Maria de Lourdes Barbosa, matriculada em 1968, e Arbernia Soares Rezende, em 1969. Também de 1968 é o livro de Waldeloir Rego no qual afirma ter sido Gato Preto o primeiro Mestre de Capoeira a ensinar mulheres, sendo, portanto, crível que antes de Luísa e Helena outras pudessem ter treinado em outras academias, tal qual a desconhecida $n^{\circ} 113$. Há que se considerar, igualmente, que não havia academias apenas no Pelourinho. Muitos mestres ensinavam em outros bairros periféricos de Salvador, como ainda hoje. Nestes locais a relação de hostilidade com a presença de mulheres pode ter sido mais ou menos severa. A academia de Mestre Gato Preto, por exemplo, não era no Centro Histórico.

O fato é que após 1963 Pastinha admitiu em sua academia, com direito a registro de informações na matrícula, duas mulheres. Tanto quanto Luísa e Helena, Maria de Lourdes e Arbenia subverteram as expectativas e normatizações de gênero e participaram de um momento de transformação da capoeira angola. Assim como Salomé, Maria Homem, Chicão, Rosa e Julia, essas duas menos conhecidas merecem maior atenção e pesquisa. Por hora apenas quis relacioná-las às incipientes mudanças culturais e de representação que ocorriam no âmbito da capoeira angola a partir do início da década de 1960.

33 FREITAS, Joseania Miranda. Uma coleção bibliográfica: os Mestres Pastinha, Bimba e Cobrinha Verde no Museu Afro-Brasileiro da UFBA. EDUFBA: Salvador, 2015. 
A pesquisa me revelou, até o momento em que escrevo este texto, apenas aquelas imagens e os dados discutidos que se descortinaram numa releitura e tessitura de nova narrativa. Quando o Viva Bahia extrapolou os muros do ICEIA e ganhou os palcos soteropolitanos, e mais tarde nacionais e internacionais, a nova era que se inaugura é a dos grupos folclóricos. Mestres da cultura popular fundaram seus próprios grupos ou expandiram as atividades de suas academias, incorporando o samba, a puxada de rede e o maculelê. Mestre João Grande lembra o período e afirmou em nossa conversa que tudo que sabe fora da capoeira, aprendeu com Emília e o Viva Bahia. "Eu não sabia cantá, sambá, batê maculelê, Emília me ensinô tudinho, ela foi minha mestra”.

Todos esses grupos folclóricos divulgaram a cultura afro-baiana e contribuíram para as transformações operadas no imaginário social compartilhado sobre tais expressões. Pensando que até mesmo a uniformização ocorreu no contexto folclorista, quando, por exemplo, Mestre Pastinha adquiriu camisas de seu querido time de futebol (Ipiranga) para que os seus discípulos usassem nas apresentações, é possível questionar quais outras características a capoeira agregou após a experiência com o folclore. Aliás, seguindo ainda a questão da indumentária, ela ajuda a compreender o grau de mudança operada neste contexto, pois em 1968 Waldeloir Rego ${ }^{34}$, que então era o maior estudioso da capoeira, afirmava que este padrão estético absorvido dos grupos folclóricos era "ridículo" e desvirtuava a tradição. Já na década de 1980, a falta do uniforme passou a ser considerada falta de fundamento e ainda hoje há rodas em que não se pode jogar sem "roupa de capoeira".

No Viva Bahia, a falta de recursos fez com que Emília Biancardi confeccionasse os trajes das apresentações com as cortinas de cetim de sua mãe. Talvez daí venha o brilho que desagradava o gosto do historiador. A presença de mulheres nos grupos folclóricos leva aos palcos uma representação diferenciada da capoeira em contraposição ao imaginário dos valentões e vadios. Claro que no caso do Viva Bahia isso durou pouco tempo, uma vez que a idealizadora das apresentações quis manter certa fidelidade ou fidedignidade, porém não faltaram oportunidades de se ver elencos $100 \%$ formados por mulheres em apresentações, por exemplo, de sua orquestra de berimbaus, a primeira que se tem notícia ${ }^{35}$.

34 REGO, Waldeloir. Idem.

35 Hoje, vários grupos de capoeira angola contam com suas orquestras de berimbaus, que costumam se apresentar em eventos diversos. A ideia de Emília nasceu quando quis homenagear sua amiga e parceira de trabalho, a folclorista Hildegardes Vianna, e preparou para ela a primeira apresentação de uma orquestra de berimbaus. Segundo relata, todas as instrumentistas da orquestra eram mulheres. 
A imagem abaixo mostra duas notícias, uma de 1965 e outra de 1966, sobre a presença do elenco do Viva Bahia na tradicional missa do Mosteiro de São Bento, quando participaram com os toques dos berimbaus e atabaques. Note que os três berimbaus ao fundo estão empunhados por mulheres, algo raro ainda hoje na roda de capoeira, onde a tradição e os fundamentos estão imbricados em mecanismos de exclusão da participação de mulheres nos "postos" de poder, como é o caso do "tocador" de berimbau numa roda de capoeira.

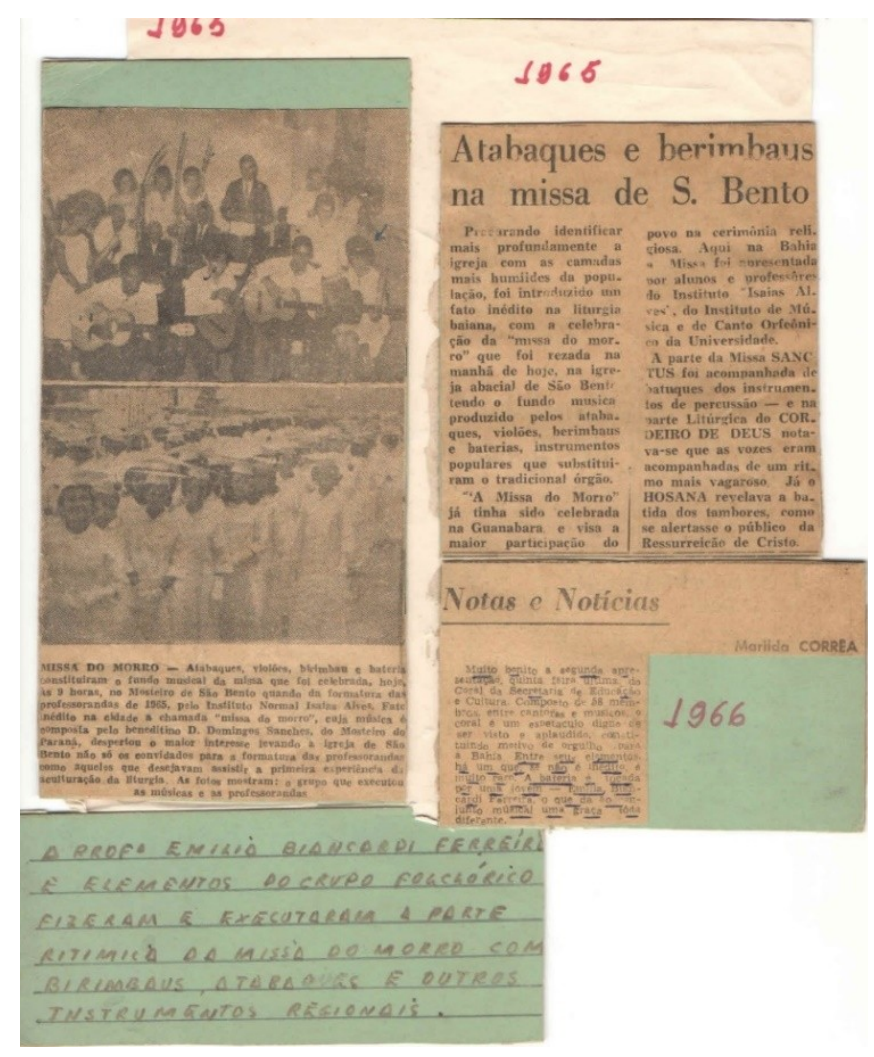

Acervo Emilia Biancardi. Centro Cultural Solar Ferrão. Mulheres ao berimbau.

É claro que o trabalho de divulgação e valorização da capoeira realizado pelos próprios mestres, desde antes de 1941, quando muitos deles se reuniam nas rodas do Gengibirra, no bairro da Liberdade, Salvador, para discutir os destinos de sua arte e a fundação de um Centro de Capoeira ${ }^{36}$, tem um peso fundamental já inscrito na historiografia, na oralidade e em diversos estudos sociais. Pouco se tem produzido, contudo, sobre as relações entre os grupos folclóricos e a capoeira. Menos ainda sobre a presença de mulheres num e noutro momento. É possível dizer, porém, que os grupos

36 COUTINHO, Daniel. O ABC da Capoeira Angola. Os manuscritos do M. Noronha. Explicações e notas de Frede Abreu. Brasília: DEFER/GDF, 1993. 
como o Viva Bahia participaram dos processos que agregaram valor e alteraram o status social e cultural da capoeira. Tais processos também podem estar relacionados à gradual entrada de mulheres nas academias após a década de 1960, sobretudo a partir da década de 1970. Portanto, Luísa Sampaio e Helena Santos podem ser mais do que uma referência à atual geração de angoleiras carentes de uma memória coletiva. Elas agenciaram - juntamente com Emília Biancardi, as demais participantes do Viva Bahia e aquelas primeiras mulheres que se inscreveram nas academias na década de 1960 - a "abertura de portas da capoeira angola" à participação das mulheres. E se os elementos androcêntricos, que por vezes persistem na análise e na prática cultural, impedissem tal abertura, arrombariam a janela ${ }^{37}$.

\section{Referências Bibliográficas}

ANDRADE, Bruno. Vadiação diaspórica: o jogo da capoeira com a modernidade brasileira. Doutoramento em Pós-colonialismos e cidadania global. Centro de Estudos Sociais/Faculdade de Economia da Universidade de Coimbra, 2011.

BARBOSA, Maria José Somerlate. A Mulher na Capoeira. In: Arizona Journal of Hispanic Cultural Studies. Vol. 09. Ano 2005.

BHABHA, Homi K. Locais da cultura, em BHABHA, Homi K. O local da cultura. Belo Horizonte: Editora UFMG, 2003.

BIANCARDI, Emília. Olelê Maculelê. Edição pela autora: Salvador, 1989.

BIANCARDI, Emília. Raízes Musicais da Bahia. Omar G: Salvador, 2000.

CARBY, Hazel. Mujeres Blancas. ¡Escuchad! El feminismo negro y los limites de la hermandad femenina. In: SOJOURNER, Truth. et. al. (org.). Feminismos Negros: una antología. Madrid: Traficantes de Sueños, 2012.

COUTINHO, Daniel. O ABC da Capoeira Angola. Os manuscritos do M. Noronha. Explicações e notas de Frede Abreu. Brasília: DEFER/GDF, 1993.

CURIEL, Ochy. Crítica poscolonial desde las práticas políticas del feminismo antirracista. In: Revista Nómadas. № 26 Abri. 2007. Universidad Central, Colombia.

DAVIS, Angela. El legado de la esclavitud: modelos para una nueva feminidad. In: DAVIS, Angela. Mujeres, raza y clase. Madrid: Akal, 2005.

DIAZ, Martin. Racismo epistémico y monocultura: Notas sobre las diversidades ausentes en América Latina. In: Revista de Epistemología y Ciencias Humanas, n. 3, Grupo IANUS, Docentes de la Universidad Nacional de Rosario y la Universidad Nacional del Litoral.

37 HALL, Stuart. Da Diáspora: Identidades e Mediações Culturais. Editora UFMG: Belo Horizonte, 2013. 
FREITAS, Joseania Miranda. Uma coleção bibliográfica: os Mestres Pastinha, Bimba e Cobrinha Verde no Museu Afro-Brasileiro da UFBA. EDUFBA: Salvador, 2015.

GROSFOGUEL, Ramón. La descolonización del conocimiento: diálogo crítico entre la visión descolonial de Frantz Fanon y la sociología descolonial de Boaventura de Sousa Santos. In: Actas del "IV Training Seminar del Foro de Jóvenes Investigadores en Dinámicas Interculturales (FJIDI)" del Centro de Estudios y Documentación Internacionales de Barcelona (CIDOB), Barcelona, 26-28 de enero de 2011.

HALL, Stuart. Da Diáspora: Identidades e Mediações Culturais. Editora UFMG: Belo Horizonte, 2013.

LANDES, Ruth. A cidade das mulheres. Rio de Janeiro: Civilização Brasileira, 1967.

LAURETIS, Teresa de. A Tecnologia do Gênero. In: HOLLANDA, Heloisa Buarque (org.). Tendências e Impasses: o feminismo como crítica da cultura. Rio de Janeiro: Rocco, 1994.

MBEMBE, Achille. Sair da Grande Noite. Ensaio sobre a África Descolonizada. Luanda, Angola; Ramada, Portugal: Edições Mulemba; Edições Pedago, 2014.

Mignolo, Walter D. A colonialidade de cabo a rabo: o hemisfério ocidental no horizonte conceitual da modernidade. En libro: A colonialidade do saber: eurocentrismo e ciências sociais. Perspectivas latino-americanas. Edgardo Lander (org). Colección Sur Sur, CLACSO, Ciudad Autónoma de Buenos Aires, Argentina. setembro 2005.

MUNIZ, Diva do Couto Gontijo. Mulheres na historiografia brasileira: práticas de silêncio e inclusão diferenciada. In: STEVENS, Cristina et. al. Gênero e feminismos: convergências (in)disciplinares. Brasília: Libris, 2010.

NEPOMUCENO, Bebel. Mulheres Negras: protagonismo ignorado. In: PINSKY, Carla Bassanezi; PEDRO, Joana Maria (org.). Nova História das Mulheres no Brasil. São Paulo: Contexto, 2012.

OLIVEIRA, Josivaldo P. de \& LEAL, Luiz Augusto P. Capoeira. Identidade e Gênero: Ensaios sobre a história social da Capoeira no Brasil. Salvador: EDUFBA, 2009.

PRIORE, Mary. História das Mulheres: As vozes do silêncio. In: FREITAS, Marcos Cezar de (org.). Historiografia Brasileira em Perspectiva. São Paulo: Contexto, 1998.

RAGO, Margareth. Epistemologia Feminista, gênero e história. In: PEDRO, Joana Maria (org.) Masculino, Feminino e Plural. Florianópolis: Editora Mulheres, 2000.

REGO, Waldeloir. Capoeira angola: ensaio sócio-etnográfico. Salvador: Itapoã, 1968.

SCOTT, Joan. História das Mulheres. In: BURKE, Peter. A escrita da história: novas perspectivas. São Paulo: Editora da UNESP, 1992.

SCOTT, Joan. Prefácio à Gender and Politics of History. Cadernos Pagu. Campinas: Unicamp/NEG/PAGU, 1994, n. 3.

SEGATO, Rita. Aníbal Quijano y la perspectiva de la colonialidad del poder. In: SEGATO, Rita. 
Sankofa. Revista de História da África e de Estudos da Diáspora Africana Ano X, NºXIX, agosto/2017

La crítica de la colonialidad em ocho ensayos y uma antropologia por demanda. Prometeo Libros: Buenos Aires, 2013.

WALLERSTEIN, Immanuel. Ler Fanon no século XXI. In: Revista Crítica de Ciências Sociais, 82, Setembro 2008. 